\title{
Periodic limb movements during sleep: a narrative review
}

\author{
Panagis Drakatos ${ }^{1,2,3 \#}$, Michelle Olaithe ${ }^{4 \#}$, Dhun Verma ${ }^{1 \#}$, Katarina Ilic ${ }^{1,5}$, Diana Cash ${ }^{1,5}$, Yaqoot Fatima ${ }^{6,7}$, \\ Sean Higgins ${ }^{1,2}$, Allan H. Young ${ }^{8}$, K. Ray Chaudhuri ${ }^{9}$, Joerg Steier ${ }^{2,3}$, Timothy Skinner ${ }^{10,11}$, \\ Romola Bucks $^{4,12}$, Ivana Rosenzweig ${ }^{1,2}$
}

\begin{abstract}
${ }^{1}$ Sleep and Brain Plasticity Centre, CNS, IoPPN, King's College London, London, UK; ${ }^{2}$ Sleep Disorders Centre, Guy's and St Thomas' Hospital, GSTT NHS, London, UK; ${ }^{3}$ Faculty of Life and Sciences Medicine, King's College London, London, UK; ${ }^{4}$ School of Psychological Science, University of Western Australia, Perth, Western Australia, Australia; ${ }^{5}$ BRAIN, Imaging Centre, CNS, King's College London, London, UK; ${ }^{6}$ Institute for Social Science Research, University of Queensland, Brisbane, Australia; ${ }^{7}$ Centre for Rural and Remote Health, James Cook University, Mount Isa, Australia; ${ }^{8}$ School of Academic Psychiatry, King's College London, London, UK; ${ }^{9}$ King's College London and Parkinson's Foundation Centre of Excellence, King's College Hospital, London, UK; ${ }^{10}$ Institute of Psychology, University of Copenhagen, Copenhagen, Denmark; ${ }^{11}$ La Trobe Rural Health School, La Trobe University, Bendigo, Victoria, Australia; ${ }^{12}$ The Raine Study, University of Western Australia, Perth, Australia Contributions: (I) Conception and design: I Rosenzweig, P Drakatos; (II) Administrative support: D Verma; (III) Provision of study materials or patients: All authors; (IV) Collection and assembly of data: All authors; (V) Data analysis and interpretation: All authors; (VI) Manuscript writing: All authors; (VII) Final approval of manuscript: All authors.

\#These authors contributed equally to this work.

Correspondence to: Dr. Ivana Rosenzweig. Sleep and Brain Plasticity Centre, Department of Neuroimaging, Box 089, Institute of Psychiatry, Psychology and Neuroscience, De Crespigny Park, London SE5 8AF, UK. Email: ivana.1.rosenzweig@kcl.ac.uk.
\end{abstract}

Objective: Using narrative review techniques, this paper evaluates the evidence for separable underlying patho-mechanisms of periodic limb movements (PLMs) to separable PLM motor patterns and phenotypes, in order to elucidate potential new treatment modalities.

Background: Periodic limb movement disorder (PLMD) is estimated to occur in 5-8\% of the paediatric population and $4-11 \%$ of the general adult population. Due to significant sleep fragmentation, PLMD can lead to functional impairment, including hyperactivity and delayed language development in children, and poor concentration and work performance in adults. Longitudinal data demonstrate that those with PLMD are at greater risk of depression and anxiety, and a 4-fold greater risk of developing dementia. PLMD has been extensively studied over the past two decades, and several key insights into the genetic, pathophysiological, and neural correlates have been proposed. Amongst these proposals is the concept of separable PLM phenotypes, proposed on the basis of nocturnal features such as the ratio of limb movements and distribution throughout the night. PLM phenotype and presentation, however, varies significantly depending on the scoring utilized and the nocturnal features examined, across age, and co-morbid clinical conditions. Furthermore, associations between these phenotypes with major neurologic and psychiatric disorders remain controversial.

Methods: In order to elucidate potential divergent biological pathways that may help clarify important new treatment modalities, this paper utilizes narrative review and evaluates the evidence linking PLM motor patterns and phenotypes with hypothesised underlying patho-mechanisms. Distinctive, underlying pathomechanisms include: a pure motor mechanism originating in the spinal cord, iron deficiency, dopamine system dysfunction, thalamic glutamatergic hyperactivity, and a more cortical-subcortical interplay. In support of the latter hypothesis, PLM rhythmicity appears tightly linked to the microarchitecture of sleep, not dissimilarly to the apnoeic/hypopneic events seen in obstructive sleep apnea (OSA).

Conclusions: This review closes with a proposal for greater investigation into the identification of potential, divergent biological pathways. To do so would require prospective, multimodal imaging clinical studies which may delineate differential responses to treatment in restless legs syndrome (RLS) without PLMS and PLMS without RLS. This could pave the way toward important new treatment modalities. 
Keywords: Periodic limb movements (PLMs); sleep; periodic limb movement phenotype (PLM phenotype)

Submitted Feb 10, 2021. Accepted for publication Oct 20, 2021.

doi: $10.21037 /$ jtd-21-1353

View this article at: https://dx.doi.org/10.21037/jtd-21-1353

\section{Introduction}

Periodic limb movements during sleep (PLMS) are involuntary, sleep-related phenomena characterized by periodic episodes of repetitive, stereotypical movements of the limbs (1-3). Lower extremities are commonly affected, with typical dorsiflexion of toes and ankles consistently reported, resembling the spinal flexor-reflex (Babinski sign), along with occasional flexion of the hip and knee. The involvement of upper limbs or other parts of the body is much less commonly recorded (4). PLMS are found in up to $80 \%$ of restless legs syndrome (RLS) cases (5), which are experienced as an unpleasant urge to move along with paresthesia- a burning or pricking sensation felt in the arms, legs or feet during periods of rest or inactivity (6). However, a much smaller percentage of patients with a polysomnographic (PSG) evidence of PLMS (22.5\%) are found to have a comorbid RLS $(4,7)$. PLMS are frequently comorbid with other sleep disorders, s variety of medical conditions (e.g., congestive heart failure, diabetes, migraine (8), cardiovascular, hepatic and renal disease, alcohol dependance, syringomyelia), and several major neurologic and psychiatric disorders (9). They can be triggered by medications and psychoactive substances, such as antidepressants and lithium (10), and they commonly increase with age, even without a comorbid sleep disorder (11). Movements similar to PLMS have been captured with polysomnography during nocturnal wakefulness (PLMW).

The diagnosis of periodic limb movement disorder (PLMD) is a diagnosis of exclusion according to the International Classification of Sleep Disorders Third Edition (ICSD-3) (12). In order for PLMD to be established, other sleep disorders associated with PLMS need to be excluded: namely the RLS $(2,13)$, narcolepsy (14), REM sleep behavior disorder (RBD), and sleep-related breathing disorder (15). Moreover, PLMS should be linked to sleep complaints or/and daytime impairment $(2,12,13,16)$.

Recent developments in the field of sleep medicine have changed our understanding of the impact of periodic motor activity on the microstructure and macrostructure of sleep and their effect on daytime functioning (17), including the modulation of the autonomic system and inflammation (18-20). As mentioned, PLMS have also been associated with significant cardiovascular and cerebrovascular risks $(21,22)$, likely due to associated sympathetic overactivity that can lead to surges in nocturnal blood pressure (BP) and heart rate (HR) without appropriate modification of the global autonomic balance (23).

Taken together, the relevant evidence summarized in this narrative review showcases accelerating research over the last two decades. The presented evidence increasingly posits that PLMS present a distinct sleep phenomenon with separate, if yet not fully delineated, physiopathology $(11,24)$.

We present the following article in accordance with the Narrative Review reporting checklist (available at https:// dx.doi.org/10.21037/jtd-21-1353).

\section{Scoring of PLMS}

Pathological PLMS are detected when their index is higher than five distinct PLM events recorded per hour of sleep. This cut-off has been extensively used in correlation studies with sleep complaints and other medical conditions, though several studies have shown that healthy subjects without sleep disorders may score above $10 \mathrm{e} / \mathrm{h}(25,26)$. Based on epidemiological studies, ICSD-3 has set the PLMI cutoff to $>15 / \mathrm{h}$ in adults and $>5 / \mathrm{h}$ in children (Table 1 ) when a diagnosis of PLMD is considered (35). As a diagnosis of exclusion, the reported sleep disturbance or functional impairment should not be better explained by another medical or mental condition (16). Identifying PLMS can be challenging in clinical practice, given that they are also associated with primary motor disorders and sleep-related breathing disorders during associated respiratory events and arousals $(13,34,36)$.

Two similar sets of updated scoring rules are currently available. The first, proposed by the World Association of Sleep Medicine (WASM), is a product of a joint task force from the International and European Restless Legs Syndrome Study group (IRLSSG and EURLSSG), and 


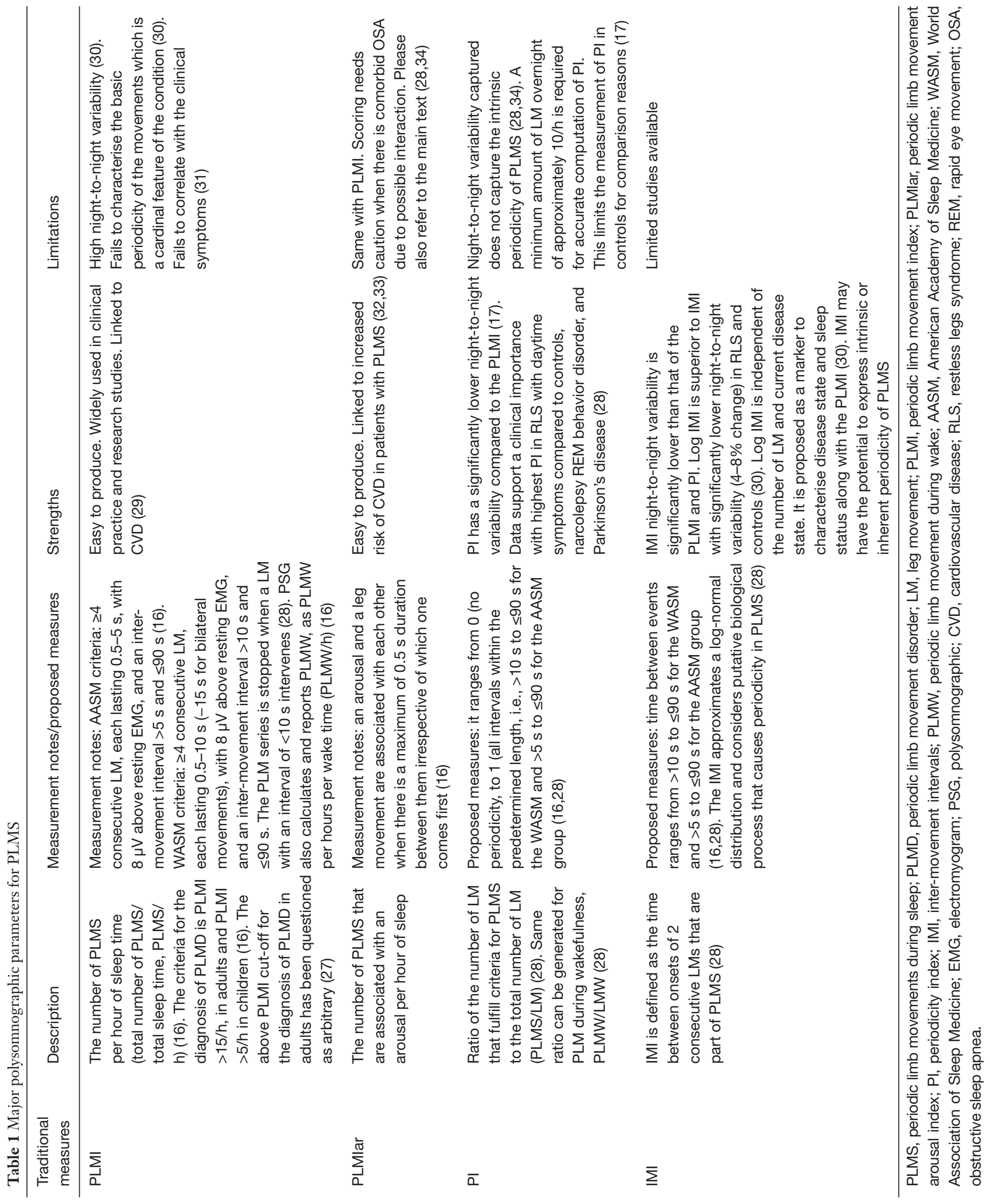


the second is issued by the American Academy of Sleep Medicine (AASM) $(28,35)$ (please refer to Table 1 for indepth list).

The AASM scoring criteria require that limb movements (LM) must occur in a series of at least four consecutive LM lasting $0.5-5$ seconds each, with an amplitude of $8 \mu \mathrm{V}$ above resting electromyogram (EMG), with an intermovement interval (both for monolateral and unilateral LM) between $\geq 5 \mathrm{~s}$ and $\leq 90 \mathrm{~s}$ to count as PLMS (35). By contrast, WASM criteria scores LM (called candidate leg movements, CLM) that may last longer, $0.5-10 \mathrm{~s}$, for monolateral CLM, and $0.5-15 \mathrm{~s}$ for bilateral, keeps the same requirement of at least 4 consecutive CLM, and with an inter movement interval adjusted to $\geq 10 \mathrm{~s}$ and $\leq 90 \mathrm{~s}$ (both for monolateral and unilateral CLM), without any CLM preceded by an interval of $<10 \mathrm{~s}$ interrupting the PLM series. The increase in the maximum duration of the CLM is proportionally increasing the inter-movement interval, to at least $10 \mathrm{~s}$, which is found to characterize these PLMS that respond to dopaminergic treatment (37). It also reduces the number of leg movements that count as PLMW due to expected reduced periodicity of the movements during wakefulness (28) (Table 1).

Both AASM and WASM rules recommend that any LM occurring within $0.5 \mathrm{~s}$ of any type of a respiratory event to be scored as respiratory event-related LM and be excluded from the PLMI. Although both criteria are detailed, their definitions have been critiqued as possibly underestimating that number $(28,35)$. Based on the results of a well designed study, the WASM group allows the extension of the time brackets to $2 \mathrm{~s}$ before and $10.25 \mathrm{~s}$ after a respiratory event, but cautions the reader that the study is yet to be replicated and was performed on a limited type of respiratory events $(28,34)$ (Table 1).

The number of arousals related to PLMS (i.e., PLMIar) is an integral part of the polysomnographic report. It may be seen as a marker of sleep fragmentation, but several studies have failed to link the PLMIar with the severity of the reported sleep complaints nor with subjective or objective sleepiness. It is worth mentioning that almost a third of the PLMS are not associated with an EEG-arousal, and in 40\% to $50 \%$ of the PLMS, the arousal precedes the onset of the motor event, which makes it difficult to maintain that the leg movement directly provokes the cortical arousal $(38,39)$. The importance of PLMIar appears to lie more in relation to the increased hazard $(5-26 \%)$ for cardiovascular events (CVE) seen in patients with PLMS $(32,33)$.

\section{PLMS phenotypes}

A number of studies over the last two decades have facilitated the identification of the phenotype of "genuine PLM" (18). Genuine PLM [inclusive of PLM during sleep (PLMS) and PLMW] comprise of two consistent features: approximately $20-40 \mathrm{~s}$ peaks in the inter-movementinterval (IMI) histogram, followed by a decline in frequency as the night progresses (40). These have consistently been observed in RLS (41-43), PLMD (27) and various other conditions, albeit with varying degrees of periodicity (44). The IMI of LM activity shows bimodal distribution in RLS with the first peak between two to four seconds and the second between 20-40 s (43). The second peak represents the periodic LM (42). These lognormal distributions intersect at ten seconds, which forms the lower threshold for genuine periodic peak with an established range between $10 \mathrm{~s}$ and $90 \mathrm{~s}$ (45) (Table 1).

Genuine PLMS can be computed using the periodicity index (PI), which is an independent measure of periodicity, and is defined as the ratio of the number of sequences with an inter-LM interval between 10 and 90 seconds/total number of inter-LM intervals (43). At least four consecutive LMs are required fulfilling the predetermined IMI interval to form PLMs, and theoretically, PI is scored as either 0 or 1, with conditions classified based on either complete absence or complete periodicity of interval lengths ranging between $10 \mathrm{~s}$ and $90 \mathrm{~s}(42,43)$ (Table 1).

Secondly, PLMS distribution throughout the night and inter-night variability also form their distinct phenotype (18). In RLS patients, PLMS are commonly recorded between $11 \mathrm{PM}$ and $3 \mathrm{AM}$, predominantly in the first half of sleep (46), with a clear decline in PLMS from the beginning to the end of sleep cycles (27). Traditionally, this has been taken to suggest that PLMS in RLS follow a circadian distribution, correlated with levels of endogenous dopamine throughout the night (47). It remains unclear if this also causes inter-night variability in PLMS (18). Characterizing the PLMS phenotype is crucial to understanding the mechanisms underlying differences in LM activity and presentations in clinical cohorts (18). For instance, only genuine PLMS respond to treatment with dopaminergic agonists $(48,49)$, and not the PLMW that tend to have a shorter IMI (50) (Table 1).

In keeping, several studies that monitored three independent parameters (i.e., PLMI, PI and time of the night LM distribution) in different clinical cohorts $(27,37,51)$ during investigations of treatment efficacies 
$(52,53)$ indicate that the degree of PLMS periodicity expression varies significantly across clinical subgroups (18). This variability likely arises due to significant differences in genetic predisposition for PLMS $(52,54,55)$.

The mean log IMI has shown the lowest night-to-night variability, compared to the PLMI, the PI and the mean MI (30). It is independent of the number of leg events at night, and reflects on the intrinsic periodicity of the PLMS, with changes over time believed to reflect individual changes (Table 1).

\section{Paediatric phenotypes}

Predictably, there is marked variability in scoring criteria for PLMS in children, depending on the age group (18). Periodicity is a rare phenomenon in paediatric PLMS $(27,42)$, which impacts the interpretation, but can be rectified by altering the diagnostic criteria to fit normative cut-offs (18). For example, the diagnostic criterion for ages five to 18 years is $>5 / \mathrm{h}(56)$, whilst the criterion for children between ages two to five years is the same in some studies (57), and higher in others $(58,59)$. Some studies indicate an increased PLMI score (up to $10.1 / \mathrm{h}$ ) in children between ages 3-5 and living at higher altitudes (60).

\section{Distribution during sleep}

PLMS commonly start during the non-rapid eye movement (NREM) stage N1, are predominant in N2, and less frequent in N3. PLMS are generally absent during REM, with exception of patients with REM behavior disorder, where PLMS are commonly recorded during REM $(61,62)$. Historically, the association of PLMS to stages N1 and $\mathrm{N} 2$ has been argued to be due to the significant link (up to $92 \%$ of the PLMS) with the cyclic alternating pattern (CAP), especially with its fast activity subtypes (A2 and A3) (63). Gradual loss of cortical control with concomitant increase in arousal threshold from $\mathrm{N} 1$ to $\mathrm{N} 3$ coincides with the emergence of a major background oscillatory arousal mechanism, the CAP (64). It has been further argued that in patients with PLMS functional changes in cortico-subcortical-spinal networks involved in generating locomotion may induce these motor patterns (64).

There are two major nocturnal patterns of PLMS. One starts shortly after sleep onset and dominates initial sleep cycles, influenced by circadian, as well as homeostatic influences (65), and a second type, where PLMS are more evenly distributed throughout the sleep cycles, with a predominant peak commonly occurring in the middle cycles of sleep. Of note is that, in both patterns, the PLMI can vary significantly between consecutive nights $(17,65,66)$. Anecdotally, it has long been acknowledged that certain body positions in susceptible individuals may also affect the genesis of PLMS. For example, in a recently published case, the generation of PLMS occurred only during the time when patient was lying in a particular position (67). The authors hypothesized that changes in body position may act to generate a deep and complex proprioceptive tactile sensory input strong enough to activate the central pattern generators linked to PLMS $(68,69)$.

\section{Epidemiology}

PLMD is estimated to occur in four to eleven \% of the general adult population (25,70-72), with age presenting an important risk factor (Table 2). As discussed previously, to date, PLMD remains a diagnosis of exclusion, and hence, most existing published studies predominantly focus on capturing the prevalence of PLMS $(\geq 15 \mathrm{e} / \mathrm{h})$ in the community, rather than prevalence of PLMD itself $(61,89,91,92)$. Several major studies, the Wisconsin sleep cohort (WSC) from the US (91), the HypnoLaus form Switzerland (61) and the SHIP-TREND/BiDirect from Germany (89), reported similar prevalence and mean age at baseline, with $28.8 \%, 28.6 \%$ and $33.3 \%$ of the participants presenting with a PLMI $>15 /$ hour with a baseline mean age of 56.1 years, 58.4 years and close to 54 years respectively. The Osteoporotic Fractures in Men (MrOS) study from US, which included only men of older age (76.5 years) showed prevalence of PLMI >15/hour at 61\% (92). Prevalence also significantly differs across ethnic groups. In a younger group (mean age 41.9 years) of 592 adult participants in tri-county Detroit, prevalence of PLMI $>15 /$ hour was $7.6 \%$ overall, and lower in African Americans ( $4.3 \%$ versus $9.3 \%$ in Caucasian) (7). Similarly, even that up to $80 \%$ of RLS patients are reported with increased PLMS $(5,21)$, this also significantly differs between various ethnic and genetic group (93). The first large-scale RLS Asian population study demonstrated two significant differences in PLMS expression: (I) lower prevalence of only $42.3 \%$, and (II) evidence that lower prevalence rates could be due to underlying differences in genetic expressions (93). However, LM periodicity and time structure characteristics did not vary across ethnicities (93).

To date, the data regarding gender-related differences for PLMS or PLMD remain conflicting, especially when 
Table 2 Risk factors for PLMS/PLMD

\begin{tabular}{|c|c|}
\hline Risk factor & Reference \\
\hline Older age & $(61,73)$ \\
\hline \multicolumn{2}{|l|}{ Drugs } \\
\hline Dopamine-receptor antagonists & $(74-76)$ \\
\hline Lithium & $(10,77)$ \\
\hline Antidepressant (SSRIs, TCA, SNRIs) & $(10,61,77,78)$ \\
\hline Hypnotics & (79) \\
\hline Anticonvulsants & $(77)$ \\
\hline \multicolumn{2}{|l|}{ Other conditions } \\
\hline Restless legs syndrome & $(61,73,80)$ \\
\hline Heart disease & $(79,81)$ \\
\hline Musculoskeletal disease & (79) \\
\hline Narcolepy with cataplexy & $(79)$ \\
\hline Chronic kidney disease & $(61,81,82)$ \\
\hline Pregnancy & $(83)$ \\
\hline Magnesium deficiency & $(84)$ \\
\hline $\begin{array}{l}\text { Neuropsychiatric and neurodegenerative } \\
\text { disorders }\end{array}$ & (85) \\
\hline Iron deficiency & $(86-88)$ \\
\hline Diabetes & $(61,89)$ \\
\hline Increased caffeine consumption ( $\geq$ six cups/day) & (79) \\
\hline Stress & (79) \\
\hline Snoring & (79) \\
\hline \multicolumn{2}{|l|}{ Habits } \\
\hline Physical inactivity & $(89,90)$ \\
\hline High BMI & $(61,89,90)$ \\
\hline Doing physical activities close to bedtime & (79) \\
\hline Being a shift or night worker & (79) \\
\hline
\end{tabular}

PLMS, periodic limb movements during sleep; PLMD, periodic limb movement disorder; SSRIs, selective-serotonin reuptake inhibitors; TCA, tricyclic anti-depressants; SNRIs, serotonin and norepinephrine reuptake inhibitors; BMI, body mass index.

polysomnography-based studies are considered (18). During pregnancy, though, and likely related to iron deficiency, there is a peak in the prevalence of RLS and PLMI $>15 /$ hour up to $25 \%$ (83).

\section{Prevalence in children}

The prevalence of a pathologically increased PLMI in children, which is set at above five events per hour, ranges between $5.6 \%$ and $8 \%$ in community-based studies (56). There is no data yet about the prevalence of PLMD in the community, with $14 \%$ prevalence reported in a pediatric sleep clinic population (94). PLMS commonly appear to precede the development of RLS in children $(95,96)$ and they are more prominent in Caucasian children with sleep disordered breathing, than in African American children (97). A large-scale study reported $25.6 \%$ of children with growing pain exhibited a PLMI $>5 / \mathrm{h}$ compared with $10.2 \%$ of children without growing pain, suggesting that growing pain could be a part of the pediatric phenotypic spectrum (98).

\section{Associated psychiatric and neurologic disorders}

Theoretically, PLMS may cause significant sleep fragmentation and lead to functional impairment $(18,99)$ through their disturbance of underlying sleep rhythms and their intrinsic functions. Unsurprisingly, patients with PLMD indeed commonly report a non-restorative sleep, excessive daytime sleepiness, poor concentration and work performances (95). In children, delayed language development and behavior problems such as increased irritability, hyperexcitability, hyperactivity, inattention, aggressiveness and social withdrawal (57), oppositional behaviors (100), and mood disorders such as anxiety and depression have all been reported (99).

Paediatric PLMD commonly presents co-morbid with the attention deficit hyperactivity disorder (ADHD). It has been suggested that up to $26-64 \%$ children with ADHD may meet PLMD diagnosis, and reciprocally, that up to $91 \%$ pediatric PLMD cases meet ADHD diagnosis $(101,102)$. The PLM-related sleep fragmentation similarly appears to be linked to the hyperactivity behavior, with significantly more PLMS linked to an arousal in the PLMD-ADHD children group compared to the PLMD without comorbidities (102). Overall, the consensus is that, in children, PLMS may trigger or worsen the symptoms of ADHD (103). Moreover, in vulnerable and susceptible children, they may increase the likelihood of nightmares, difficulty in sleep initiation, as well as increase the risk of monosymptomatic and refractory enuresis (104).

In keeping with many other sleep disorders (105), PLMD and RLS share bidirectional links with several major psychiatric and neurologic disorders (106). Both are commonly diagnosed sleep comorbidities in numerous neurologic and neurodegenerative diseases (85) including alpha-synucleinopathies (62), Alzheimer's disease (107), multiple sclerosis (108), multiple system atrophy (109), corticobasal degeneration (76) and amyotrophic lateral 
sclerosis (110), spinal cord injury (111), Gilles de la Tourette syndrome $(112,113)$, stroke (114), and several functional disorders including chronic pain (115), chronic fatigue (116) and fibromyalgia (117). However, the mechanisms underlying those links are far from clear (118). Several studies have illustrated structural and functional alterations in distinct brain regions of the patients, with similar areas reported in animal models with RLS/PLMD, but no unifying mechanism has yet been identified (119).

A recent retrospective longitudinal study, conducted using the national health insurance research database in Taiwan, reported four major findings: (I) sleep-related movement disorders increased the risk of developing allcause dementia by four times, (II) patients aged 45-64 years had higher associated risk, (III) women were more susceptible than men and (IV) dementia risk was timedependent and increased progressively over time (107). In keeping, frequent PLMS have also been independently associated with cognitive decline, with largest effects on the cognitive domain of executive function among older men, even in the absence of an overt diagnosis of dementia (120). In the same vein, prevalence studies of PLMS in Parkinson's disease (PD) confirm an increased prevalence of PLMD in PD $(121,122)$. Limited pathophysiologic evidence suggests nigrostriatal degeneration, along with a reduced striatal dopamine transporter binding in PD patients with PLMS, as a shared pathophysiological basis for both disorders (123).

A small number of studies have over the years examined the link between PLMS and other neurologic disorders, and the links with multiple sclerosis have been amongst those most studied. MS patients with PLMS have been shown to have a significantly higher disability (124). Prevalence of $32.5 \%$, of increased PLMI $>15 / \mathrm{h}$ has been suggested in one study of MS patients (125). A disinhibition of the lower spinal network due to cervical or supraspinal MS lesions has been proposed as one of the possible underlying mechanisms (125). Yet another study suggested a $12 \%$ prevalence of PLMI $>21 / \mathrm{h}$ in patient with MS (126). Critically, patients with MS may experience PLMS during REM, which arguably may explain a greater likelihood of disability noted (124).

The data linking adult PLMD and psychiatric disorders is potentially even more conflicting. For example, in a recent cross-sectional study of idiopathic RLS patients, presence of PLMS did not reflect on quality of life (127). In addition, lack of PLMS was found to be associated with significantly higher depression and anxiety among RLS patients, and RLS patients without PLMS had distinct PSG parameters such as lower total arousal index, longer latency to REM, and a higher spontaneous arousal frequency than RLS patients with PLMS (127). The authors argued that high prevalence of RLS without PLMS in their carefully characterized clinical sample questions the presumed shared pathomechanism between RLS and PLMS for a substantial portion of RLS patients. Moreover, the authors of the study argued that their findings may be taken to suggest separate neuromechanisms at play. Another distinct finding in this study was the high prevalence $(65.1 \%)$ of clinically significant depression in the RLS patients who did not have co-morbid PLMS (127). Previous reports also go some way to support this notion, with patients with RLS and without PLMS reported to have higher rates of psychiatric comorbidities and higher risk for clinical depression $(127,128)$. Of note, patients with RLS without PLMS have been shown to be treatment-resistant to dopaminergic therapy (128). Interestingly, another Korean study reported significantly more severe anxiety and depressive symptoms in RLS patients with lower PLMI (129). In keeping, another study that compared neuropsychiatric symptoms in patients with PLMD to those with RLS highlighted a higher psychosomatic burden in the RLS patients (130). In this study, RLS patients also showed a higher somatization burden (130). Future prospective studies should closely examine whether PLMS status has any bearing on the paindepression-anxiety relationship in RLS, and whether it independently predisposes for any distinct neurologic or psychiatric phenotype.

\section{Risk factors}

Amongst recognized risk factors (Table 2), age, male gender and RLS have all been recorded as independent risk factors for PLMS in adults (PLMI $>15 / \mathrm{h}$ ) in communitybased studies $(61,73,80)$. The impact of lifestyle-related factors on PLMS exacerbation, on the other hand, remains controversial. Physical inactivity has been linked to higher PLMI and vice versa $(89,90)$. Moreover, two small-scale studies in PLMD patients reported a reduction in PLMI following a single session of maximum effort physical training $(131,132)$ and an increase in $\beta$-endorphin values (132). Such studies suggest the involvement of the opioid system, albeit large-scale epidemiologic and intervention studies are needed. Data on smoking habit and PLMS remain controversial (133).

Several psychotropic medications have been linked to PLMI above 15 events per hour (78). For example, whilst 
dopamine-receptor antagonists, anticonvulsants, and lithium can potentially precipitate PLMS symptoms, it is typically the antidepressants, including selective-serotonin reuptake inhibitors (SSRIs; including sertraline), tricyclic anti-depressants (TCA; e.g., amitriptyline), and serotonin and norepinephrine reuptake inhibitors (SNRIs; e.g., venlafaxine and mirtazapine) which have been linked to pharmacologically induced PLMs (77). However, several antidepressants have been identified that do not appear to precipitate PLMs and are hence clinically recommended in affected or vulnerable patients, namely trazodone, bupropion (134), nefazodone and doxepin $(10,135)$.

Serum ferritin has been the focus of several studies with controversial results likely reflecting different phenotypes $(89,136)$. However, iron supplementation remains a part of the treatment pathway in patients with RLS/PLMD and with serum ferritin levels at the lower end of normal range (137). Studies on magnesium $\left(\mathrm{Mg}^{++}\right)$and PLMS are rare, with one community based study supporting low levels as an independent determinant of PLMI $>15 / \mathrm{h}$, and a small interventional study showing reduction in the PLMI in patients with RLS or insomnia (84).

Chronic kidney disease (CKD) and renal failure have been similarly linked with RLS and PLMS $(81,82)$. Diabetes has also been reported as potential risk factors for PLMI $>15 / \mathrm{h}$, however, this relationship weakens when adjusting for other confounding factors is done $(61,89)$. Although PLMS and obstructive sleep apnea (OSA) may commonly coexist, community-based studies have to date failed to detect any overt relationship between PLMI and AHI $(61,80)$.

\section{Pathomechanisms}

The mechanistic framework that underlies PLMS pathophysiology and aetiology is far from clearly defined. Over the years, three major anatomical loci have been similarly fervently argued as the potential locus minoris resistentiae: a neocortical, subcortical and the spinal cord. The hyperexcitability of spinal flexor pathways, especially during NREM sleep, could arguably link to increased PLMS, with dopamine deficiency triggering these pathways in some susceptible individuals (1). Nonetheless, EEG, autonomic and sympathetic cortical activations following PLMS are a well-established finding. However, the data on whether similar activations reliably precede all the PLMS remains contradictory. Post PLMS cortical activation has been reported in the alpha and beta EEG bands, with increased heart rate and systolic and diastolic blood pressure too (138-140). Other studies have shown an increase in EEG activity in the delta band and HR seconds before the leg movement (141-143). Conversely, these findings have been taken by some clinicians to suggest that the PLMS are simply the motor manifestation of an increased sympathetic/autonomic status. Interestingly, when cortical arousals and PLMS are iatrogenically disconnected by benzodiazepine intake, this minimizes the EEG activation but it does not appear to affect the PLMS $(144,145)$. Conversely, dopamine agonists have been reported to have the opposite effect $(144,145)$. Two distinctive underlying pathomechanisms have been argued in that background: a pure motor, and possible originating in the spinal cord, and a more cortical-subcortical interplay. In putative support of the latter hypothesis, it has been shown that the PLMS rhythmicity appears tightly linked to the microarchitecture of sleep, and its CAP periodicity, not dissimilarly to the apnoeic/hypopneic events in OSA (146). Moreover, PLMS are rarely recorded during the $\mathrm{B}$ phase of $\mathrm{CAP}$, a period of a low EEG activation which does not appear to support the emergence of PLMS, which are instead typically confined to CAP's A phases.

PLMS are, however, less stereotyped than previously believed, with individual variations recorded widely in motor patterns, muscle sequence activation and the groups of muscles involved $(17,147)$. PLMS commonly occur either on one leg or they can as easily alternate between the two limbs (10). According to the EMG activity the distinct motor patterns in PLMS may include: (I) tonic activity lasting several hundreds of milliseconds followed by myoclonic activity, (II) an initial myoclonic jerk followed by tonic activity, (III) several clusters of myoclonic jerks sometimes followed by tonic activity (148).

Typically, PLMS are most prominent in the tibialis anterior (TA) muscle $(75 \%)$ and therefore are primarily recorded there during clinical investigations (96). Other activated muscle groups include gastrocnemius $(60 \%)$, biceps femoris (55\%), and rectus femoris (40\%) (149), and less frequently their antagonistic muscles groups (21). Upper limb muscles are infrequently involved, and axial muscles even less frequently (18). On EMG, $53 \%$ of the PLMS initiate in the TA, $18 \%$ in the gastrocnemius, $13 \%$ in the biceps femoris and $7 \%$ in the rectus femoris muscle groups respectively (149). Several groups have argued that based on this anatomical distribution, TA muscle activity likely falls under the category of "central pattern generators" (CPG), and that this spread of PLMS activity may reflect a subcortical origin of PLMS. Furthermore, 
it has been argued that this asynchronous activations of the leg muscles with partially or totally disconnected supratentorial and spinal structures $(39,150,151)$ may theoretically suggest the possibility of two distinctly independent spinal pattern generators (one on either side of the body) which integrate to form a more complex mechanism, sharing anatomical as well as functional pathways. Accordingly, multiple supraspinal mechanisms that can work in a coordinated manner have been identified thus far (152). The descending supraspinal mechanisms have further been implicated in modulating PLMS, which according to this hypothesis, could initially arise from the brainstem reticular system (7). An indirect evidence from a transcranial direct-current stimulation (tDCS) study in RLS patients suggest that the periodicity of PLMS arises due to spinal motor and brainstem hyperexcitability (153). Some imaging studies, on the other hand, have been potentially taken to implicate the role of the sympathetic nervous system and the red nucleus of the brain stem in triggering PLMS (154). Synchronization of large-scale cortical motor neurocircuitry comprising pericentral, dorsolateral, prefrontal and cingulate regions of the brain has been recorded in delta band prior to motor demonstration of PLMS (155). In addition, activity in those areas and the default mode network, appeared significantly associated with PLMI severity scores (155).

\section{Iron, dopamine and glutamate}

The role for iron deficiency in the pathophysiological processes of RLS is recognized (88). $25 \%$ of RLS patients suffer with iron deficiency (86), and $43 \%$ of iron deficient patients experience symptoms of leg restlessness (87). Moreover, RLS symptom severity is associated with lownormal range of serum ferritin (156). Conversely, the role of iron deficiency in PLMs without RLS remains largely unexplored, despite its well-established role in RLS with PLMS (157).

Similarly, considerable pharmacological and clinical evidence supports dopamine system dysfunction as critical in RLS pathophysiology (158). It is well-established that RLS symptoms improve when patients are administered dopaminergic medications (159), but can also experience worsening of their symptoms (augmentation effect) at a rate of $8 \%$ per year on treatment $(160,161)$. Dopamine agonists need to cross the blood brain barrier in order to alleviate RLS symptoms suggesting that dopamine plays a central role in RLS pathophysiology (162). Moreover, iron is a co- factor of tyrosine hydroxylase, a rate limiting step enzyme involved in the conversion of levodopa to dopamine in the brain (163). Thus, inadequate iron supply to the brain can alter dopaminergic signaling in the brain (157). Animal studies report a decrease in extracellular dopamine levels, of its D1, D2 receptors, and of the dopamine-transporter density in the striatum of iron-deficient rodents (164). Furthermore, neurodevelopmental studies reveal shortand long-term alterations associated with neonatal iron deficiency, leading to major biological alterations in dopamine pathways (165). For instance, impaired dopamine function in the nigrostriatal pathway may result in poorer motor sequencing during tests (166). Dopaminergic A11 cells are located in the midbrain, and they are the sole source of dopamine in the spinal cord via long and diffuse axonal projections (167) that cross over from the dorsal horn into the motor neuronal junction $(157,168)$. Reduced drive or damage of this system, as evidenced by stereotaxic bilateral 6-hydroxydopamine lesion in animal studies, can cause changes consistent with RLS (169).

Of note, in animal studies, opioid treatment and an intact endogenous opioid system have been shown to have a neuroprotective effect on the dopaminergic cells in cases of iron deficiency (170), suggesting a new set of molecular pathways for newer therapies.

Thalamic glutamatergic hyperactivity has also been recently associated with both RLS and PLMS $(171,172)$. This pathomechanism may underlie the clinical benefit that the RLS and PLMD patients receive from the $a-2-\delta$ anticonvulsants (e.g., pregabaline and gabapentine), with more significant effects on the quality of sleep, than on the reduction of PLMI (173). The link between all three systems has been suggested by the findings in iron deficient animal models where an increased glutamate activity has been demonstrated in several brain regions $(174,175)$.

\section{Genetics}

Familial cases of early-onset RLS and PLMS have been identified (Table 3), with heritability greater than $60 \%(189,190)$. Genetic linkage studies in familial RLS identified several chromosomal loci (179), namely-RLS1 on chromosome $12 \mathrm{q}$ discovered in a French-Canadian family (177), RLS2 on Chr14q observed in an Italian family (176), $R L S 3$ on Chr9p in 15 extended American families (178), RLS4 ON Chr2q and RLS5 on Chr20p (180) respectively. These transmissions are autosomal dominant with incomplete penetrance (191). Additionally, high 
Table 3 Genetic causes of RLS and PLMS

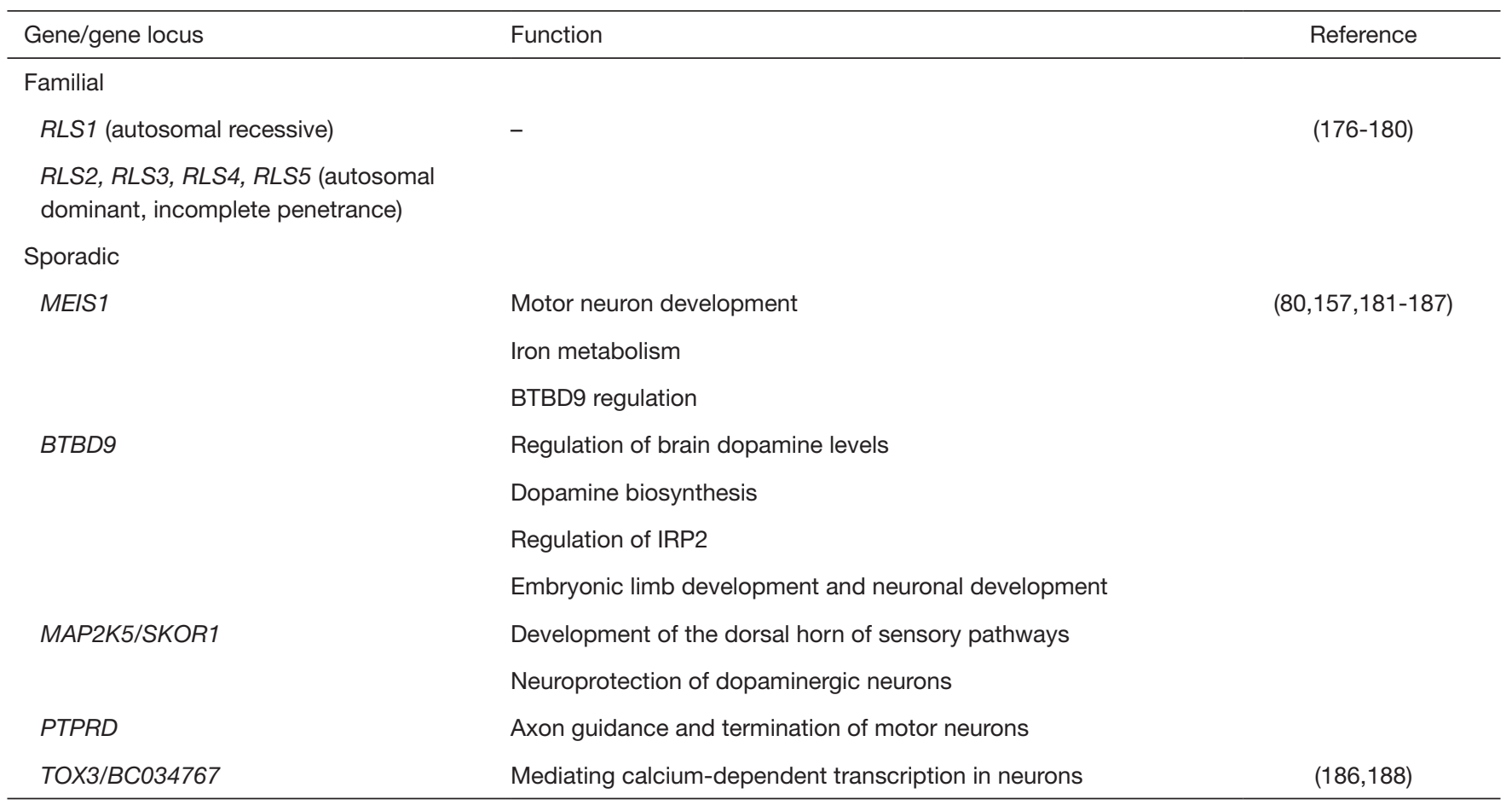

RLS, restless legs syndrome; PLMS, periodic limb movements during sleep.

concordance has been reported in monozygotic twins $(169,192)$.

Genome wide association studies (GWAS) have similarly identified four susceptibility candidate genes and single nucleotide polymorphisms (SNPs) strongly associated with PLMS, namely: rs12469063 and rs2300478 of MEIS1, rs3923809 and rs9357271 of BTBD9, rs6494696 of MAP2K5/ SKOR1 $(80,187)$ and TOX3/BC034767 on chromosome 16q12.1 (Figure 1) (194,195). Each genetic variant carries an increased risk of up to $50 \%$ in RLS (187). These genes have been suggested to play role in embryonic limb development and neuronal development (162). For example, MEIS1 gene (chromosome $2 \mathrm{p} 14$ ) is involved in regulatory network crucial for motor neuron development, and it is expressed in substantia nigra (196). On the other hand, each risk allele of BTBD9 (chromosome 6p21.2) has been associated with a $13 \%$ decrease in ferritin levels, a known risk factor for RLS (195). Moreover, SKOR1 gene, previously called LBXCOR1 has been suggested to play the role in regulation of development of the dorsal horn of sensory pathways (191). Additionally, two SNPs have been expressed in the rs1975197 of Protein Tyrosine Phosphate, Receptor type, D (PTPRD) gene (chromosome 9p24.1-p23), which is involved in neuronal development (194). In the Wisconsin sleep cohort
(WSC), the most prominent genetic associations were established in TOX3/BC034767, MEIS1 and BTBD9 with both RLS and PLMs (197). Moreover, MEIS1 SNPs were most strongly linked with PLMs in the absence of RLS (80). In RLS patients autopsy studies, the MEIS1 gene was also found to be associated with increased thalamic expression of H-ferritin, L-ferritin and divalent metal transporter1RNA (181), which suggested that MEIS1 mutant alleles predisposed patients to iron deficient conditions.

Similarly, another study has reported that blocked MEIS1 mRNA expression leads to increased transferrin-2 receptor, ferroprotein mRNA and BTBD9 gene expression, while hepcidin mRNA expression decreased after 48 hours, thereby inferring the role of MEIS1 gene in controlling intracellular iron transfer to mitochondria, extracellular iron export and potential effects on the BTBD9 gene expression and its function in the downregulation of iron (184). While MEIS1 regulates iron homeostasis, BTBD9 was observed to significantly reduce brain dopamine levels and led to an abnormal sleep pattern in mutant flies (182). The $B T B D 9$ gene modulates transcription of ion conductance, cytoskeletal arrangement and protein ubiquitination and it enhances activity in rat striatum, a part of basal ganglia involved in voluntary movement in addition to largely 

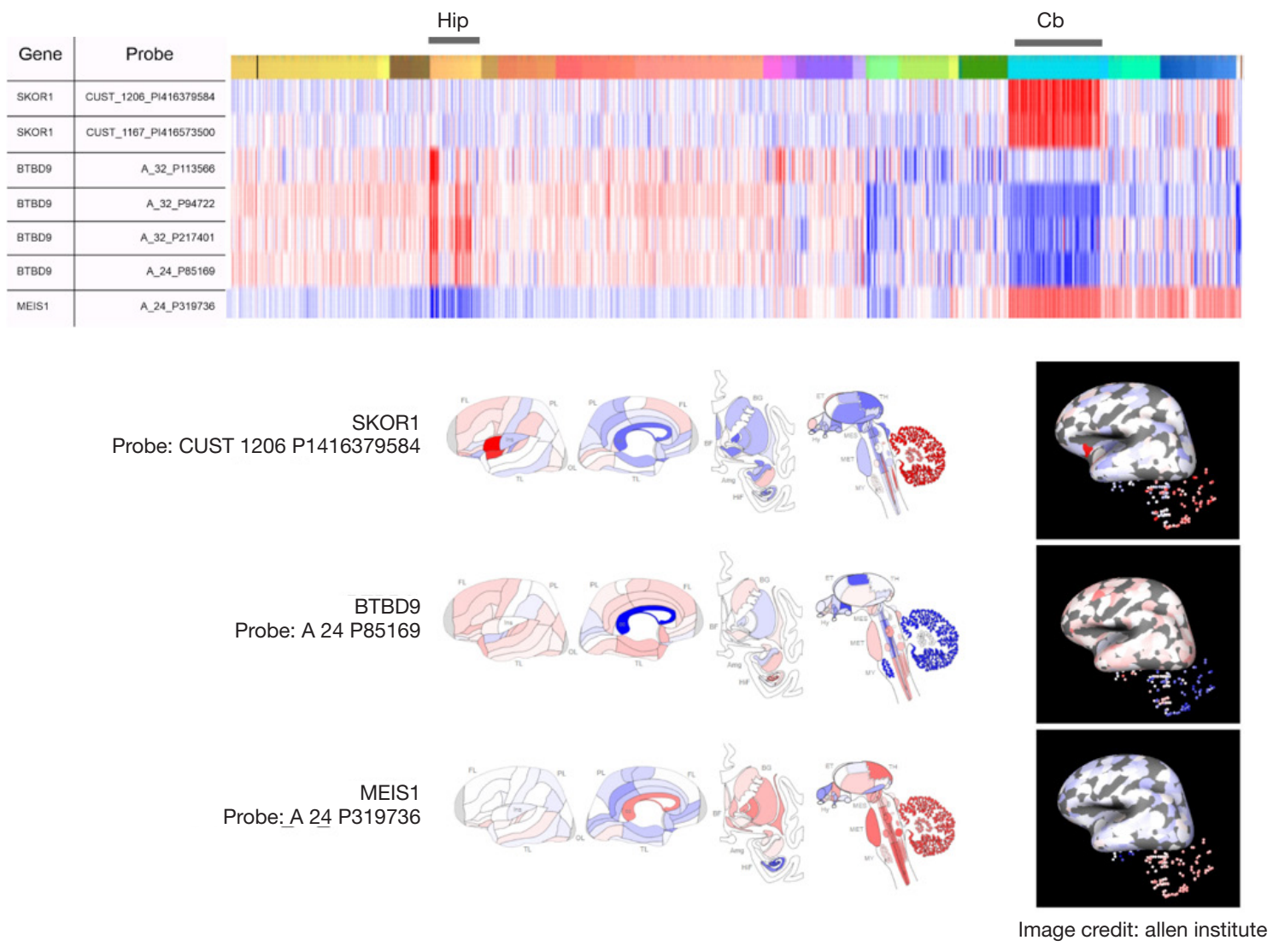

Figure 1 Genes associated with PLMS. Levels of gene expression for SKOR1, BTBD9 and MEIS1 across different anatomical regions of the human brain as heatmaps or as drawings are shown. SKOR1 and MEIS show highest expression in the Cb, while BTBD9 shows highest expression in hippocampal regions (Hip). Donor H0351.1016; adapted and data available from Human Brain Atlas of Allen Institute (193). Amg, amygdala; BG, basal ganglia; Cb, cerebellum; ET, epithalamus; FL, frontal lobe; HiF, hippocampal formation; Hy, hypothalamus; INS, insula; MES, mesencephalon; MET, metencephalon; Mid, midbrain; MY, myelencephalon; OL, occipital lobe; Pons, pons; PL, parietal lobe; TH, thalamus; TL, temporal lobe; PLMS, periodic limb movements during sleep.

comprising of dopaminergic neurons containing both D1 and D2 receptors (157). A study reported under expression of this gene causes hyperactivity and hyperexcitability in the calcium-gated dopaminergic neurons in striatum (198).

In summary, clinical implications and diverse phenotypes of PLMS are increasingly recognized. Several computerized and data-driven assessment techniques have been proposed to facilitate the analysis of intrinsic periodicity of PLM during both sleep and wakefulness. However, their phenotype and presentations vary vastly, across age and co-morbid clinical conditions. These motor patterns are influenced not just by their intrinsic regulatory and oscillatory mechanisms, but also neurophysiological cofactors- dopamine and iron. Furthermore, sensory inputs can alter the activity of these intrinsic motor pattern generators and fluctuations in iron and dopamine reportedly cause significant exacerbations of symptoms.

Their links with major neurologic and psychiatric disorders remain controversial. In the future, prospective, multimodal imaging clinical studies should help delineate differential responses to treatment in RLS without PLMS and PLMS without RLS. This could pave a way toward identification of potential divergent biological pathways and the important new treatment modalities.

\section{Acknowledgments}

Funding: None.

\section{Footnote}

Provenance and Peer Review: This article was commissioned 
by the editorial office, Fournal of Thoracic Disease for the series "Sleep Section". The article has undergone external peer review.

Reporting Checklist: The authors have completed the Narrative Review reporting checklist. Available at https:// dx.doi.org/10.21037/jtd-21-1353

Conflicts of Interest: All authors have completed the ICMJE uniform disclosure form (available at https://dx.doi. org/10.21037/jtd-21-1353). YF has received funding from the Medical Research Future Fund, National Health and Medical Research Council, Tropical Australian Academic Health Centre, Western Queensland Primary Health Network, Health, and Wellbeing Queensland and Queensland Health. AHY is employed by King's College London; Honorary Consultant SLaM (NHS UK); AHY is Deputy Editor of BJPsych Open; AHY gives paid lectures and is on advisory boards for the following companies with drugs used in affective and related disorders: Astrazenaca, Eli Lilly, Lundbeck, Sunovion, Servier, Livanova, Janssen, Allegan, Bionomics, Sumitomo Dainippon Pharma, COMPASS, Sage, Novartis; AHY is consultant to Johnson \& Johnson, and consultant to Livanova. KRC is on advisory board: AbbVie, UCB, GKC, Bial, Cynapsus, Lobsor, Stada, Medtronic, Zambon, Profile, Sunovion, Roche, Therevance, Scion, Britannia, Acadia, 4D; KRC receives grants (Investigator Initiated) from: Britania Pharmaceuticals, AbbVie, UCB, GKC, Bial; receives aacdemic grants: EU, IMI EU, Horizon 2020, Parkinson's UK, NIHR, PDNMG, EU (Horizon 2020), Kirby Laing Foundation, NPF, MRC, Wellcome Trust. KRC is honoraria for lectures: AbbVie, Britannia, UCB, Zambon, Novartis, Boeringer Ingelheim, Bial, Kyowa Kirin, SK Pharma. KRC receives royalties from Oxford and Cambridge publishers. JS serves as an unpaid editorial board member of Fournal of Thoracic Disease. The other authors have no conflicts of interest to declare.

Ethical Statement: The authors are accountable for all aspects of the work in ensuring that questions related to the accuracy or integrity of any part of the work are appropriately investigated and resolved.

Open Access Statement: This is an Open Access article distributed in accordance with the Creative Commons Attribution-NonCommercial-NoDerivs 4.0 International License (CC BY-NC-ND 4.0), which permits the noncommercial replication and distribution of the article with the strict proviso that no changes or edits are made and the original work is properly cited (including links to both the formal publication through the relevant DOI and the license). See: https://creativecommons.org/licenses/by-nc-nd/4.0/.

\section{References}

1. Joseph V, Nagalli S. Periodic Limb Movement Disorder. Treasure Island, FL: StatPearls, 2020.

2. Stefani A, Högl B. Diagnostic Criteria, Differential Diagnosis, and Treatment of Minor Motor Activity and Less Well-Known Movement Disorders of Sleep. Curr Treat Options Neurol 2019;21:1.

3. Sateia MJ. International classification of sleep disordersthird edition: highlights and modifications. Chest 2014;146:1387-94.

4. Chokroverty S. Sleep Disorders Medicine Basic Science, Technical Considerations and Clinical Aspects. 4th ed. New York, NY: Springer, 2017.

5. Montplaisir J, Boucher S, Poirier G, et al. Clinical, polysomnographic, and genetic characteristics of restless legs syndrome: a study of 133 patients diagnosed with new standard criteria. Mov Disord 1997;12:61-5.

6. Nair AK, Sabbagh MN. Geriatric Neurology. Handbook of clinical neurology, vol 167. Hoboken: Wiley, 2014.

7. Scofield H, Roth T, Drake C. Periodic limb movements during sleep: population prevalence, clinical correlates, and racial differences. Sleep 2008;31:1221-7.

8. Tiseo C, Vacca A, Felbush A, et al. Migraine and sleep disorders: a systematic review. J Headache Pain 2020;21:126.

9. Figorilli M, Puligheddu M, Congiu P, et al. The Clinical Importance of Periodic Leg Movements in Sleep. Curr Treat Options Neurol 2017;19:10.

10. Kolla BP, Mansukhani MP, Bostwick JM. The influence of antidepressants on restless legs syndrome and periodic limb movements: A systematic review. Sleep Med Rev 2018;38:131-40.

11. Vetrugno R, D'Angelo R, Montagna P. Periodic limb movements in sleep and periodic limb movement disorder. Neurol Sci 2007;28 Suppl 1:S9-S14.

12. International Classification of Sleep Disorders - Third Edition (ICSD-3). Darien, IL: American Academy of Sleep Medicine, 2014.

13. Trenkwalder C, Allen R, Högl B, et al. Comorbidities, treatment, and pathophysiology in restless legs syndrome. Lancet Neurol 2018;17:994-1005.

14. Pizza F, Tartarotti S, Poryazova R, et al. Sleep-disordered 
breathing and periodic limb movements in narcolepsy with cataplexy: a systematic analysis of 35 consecutive patients. Eur Neurol 2013;70:22-6.

15. Budhiraja R, Javaheri S, Pavlova MK, et al. Prevalence and correlates of periodic limb movements in OSA and the effect of CPAP therapy. Neurology 2020;94:e1820-7.

16. Berry RB, Brooks R, Gamaldo CE, et al. For the American Academy of Sleep Medicine the AASM manual for the scoring of sleep and associated events: rules, terminology and technical specifications. Darien, IL: American Academy of Sleep Medicine, 2014.

17. Ferri R, Fulda S, Manconi M, et al. Night-to-night variability of periodic leg movements during sleep in restless legs syndrome and periodic limb movement disorder: comparison between the periodicity index and the PLMS index. Sleep Med 2013;14:293-6.

18. Ferri R, Koo BB, Picchietti DL, et al. Periodic leg movements during sleep: phenotype, neurophysiology, and clinical significance. Sleep Med 2017;31:29-38.

19. Si W. Periodic limb movements of sleep in patients with history of stroke. Sleep Med 2015;16:S21.

20. Polsek D, Cash D, Veronese M, et al. The innate immune toll-like-receptor-2 modulates the depressogenic and anorexiolytic neuroinflammatory response in obstructive sleep apnoea. Sci Rep 2020;10:11475.

21. Ferri R, Novelli L, Bruni O. Periodic Limb Movement Disorder . Reference Module in Neuroscience and Biobehavioral Psychology. Elsevier, 2017.

22. Haba-Rubio J, Marti-Soler H, Tobback N, et al. Clinical significance of periodic limb movements during sleep: the HypnoLaus study. Sleep Med 2018;41:45-50.

23. Chou CH, Yin JH, Chen SY, et al. The potential impact of sleep-related movement disorders on stroke risk: a population-based longitudinal study. QJM 2017;110:649-55.

24. Fulda S. Periodic Limb Movement Disorder: a Clinical Update. Curr Sleep Med Rep 2018;4:39-49.

25. Hornyak M, Feige B, Riemann D, et al. Periodic leg movements in sleep and periodic limb movement disorder: prevalence, clinical significance and treatment. Sleep Med Rev 2006;10:169-77.

26. Stefani A, Heidbreder A, Hackner H, et al. Validation of a leg movements count and periodic leg movements analysis in a custom polysomnography system. BMC Neurol 2017;17:42.

27. Ferri R, Gschliesser V, Frauscher B, et al. Periodic leg movements during sleep and periodic limb movement disorder in patients presenting with unexplained insomnia. Clin Neurophysiol 2009;120:257-63.
28. Ferri R, Fulda S, Allen RP, et al. World Association of Sleep Medicine (WASM) 2016 standards for recording and scoring leg movements in polysomnograms developed by a joint task force from the International and the European Restless Legs Syndrome Study Groups (IRLSSG and EURLSSG). Sleep Med 2016;26:86-95.

29. Walters AS, Rye DB. Review of the relationship of restless legs syndrome and periodic limb movements in sleep to hypertension, heart disease, and stroke. Sleep 2009;32:589-97.

30. Skeba P, Hiranniramol K, Earley CJ, et al. Inter-movement interval as a primary stable measure of periodic limb movements of sleep. Sleep Med 2016;17:138-43.

31. Mendelson WB. Are periodic leg movements associated with clinical sleep disturbance? Sleep 1996;19:219-23.

32. Kendzerska T, Kamra M, Murray BJ, et al. Incident Cardiovascular Events and Death in Individuals With Restless Legs Syndrome or Periodic Limb Movements in Sleep: A Systematic Review. Sleep 2017;40. doi: 10.1093/ sleep/zsx013.

33. Koo BB, Blackwell T, Ancoli-Israel S, et al. Association of incident cardiovascular disease with periodic limb movements during sleep in older men: outcomes of sleep disorders in older men (MrOS) study. Circulation 2011;124:1223-31.

34. Manconi M, Zavalko I, Fanfulla F, et al. An evidencebased recommendation for a new definition of respiratoryrelated leg movements. Sleep 2015;38:295-304.

35. Berry RB, Brooks R, Gamaldo C, et al. AASM Scoring Manual Updates for 2017 (Version 2.4). J Clin Sleep Med 2017;13:665-6.

36. Wetter TC, Trenkwalder C, Gershanik O, et al. Polysomnographic measures in Parkinson's disease: a comparison between patients with and without REM sleep disturbances. Wien Klin Wochenschr 2001;113:249-53.

37. Manconi M, Ferri R, Feroah TR, et al. Defining the boundaries of the response of sleep leg movements to a single dose of dopamine agonist. Sleep 2008;31:1229-37.

38. Ferri R, Rundo F, Zucconi M, et al. An Evidencebased Analysis of the Association between Periodic Leg Movements during Sleep and Arousals in Restless Legs Syndrome. Sleep 2015;38:919-24.

39. Gosselin N, Lanfranchi P, Michaud M, et al. Age and gender effects on heart rate activation associated with periodic leg movements in patients with restless legs syndrome. Clin Neurophysiol 2003;114:2188-95.

40. Ferri R. The time structure of leg movement activity during sleep: the theory behind the practice. Sleep Med 
2012;13:433-41.

41. Ferri R. Two legs, one heart, one sleeping brain. Sleep Med 2006;7:299-300.

42. Ferri R, Manconi M, Lanuzza B, et al. Age-related changes in periodic leg movements during sleep in patients with restless legs syndrome. Sleep Med 2008;9:790-8.

43. Ferri R, Zucconi M, Manconi M, et al. New approaches to the study of periodic leg movements during sleep in restless legs syndrome. Sleep 2006;29:759-69.

44. Manconi M, Ferri R, Zucconi M, et al. Time structure analysis of leg movements during sleep in REM sleep behavior disorder. Sleep 2007;30:1779-85.

45. Ferri R, Manconi M, Rundo F, et al. A Data-Driven Analysis of the Rules Defining Bilateral Leg Movements during Sleep. Sleep 2016;39:413-21.

46. Sforza E, Haba-Rubio J. Night-to-night variability in periodic leg movements in patients with restless legs syndrome. Sleep Med 2005;6:259-67.

47. Hening W. The clinical neurophysiology of the restless legs syndrome and periodic limb movements. Part I: diagnosis, assessment, and characterization. Clin Neurophysiol 2004;115:1965-74.

48. Manconi M, Ferri R, Zucconi M, et al. Preferential D2 or preferential D3 dopamine agonists in restless legs syndrome. Neurology 2011;77:110-7.

49. Manconi M, Ferri R, Zucconi M, et al. Effects of acute dopamine-agonist treatment in restless legs syndrome on heart rate variability during sleep. Sleep Med 2011;12:47-55.

50. Ferri R, Manconi M, Plazzi G, et al. Leg movements during wakefulness in restless legs syndrome: time structure and relationships with periodic leg movements during sleep. Sleep Med 2012;13:529-35.

51. Ferri R, Franceschini C, Zucconi M, et al. Sleep polygraphic study of children and adolescents with narcolepsy/cataplexy. Dev Neuropsychol 2009;34:523-38.

52. Ferri R, Rundo F, Zucconi M, et al. Putting the periodicity back into the periodic leg movement index: an alternative data-driven algorithm for the computation of this index during sleep and wakefulness. Sleep Med 2015;16:1229-35.

53. Manconi M, Ferri R, Zucconi M, et al. Pramipexole versus ropinirole: polysomnographic acute effects in restless legs syndrome. Mov Disord 2011;26:892-5.

54. Puligheddu M, Figorilli M, Aricò D, et al. Time structure of leg movement activity during sleep in untreated Parkinson disease and effects of dopaminergic treatment. Sleep Med 2014;15:816-24.

55. Vendrame M, Zarowski M, Loddenkemper T, et al.
Selective serotonin reuptake inhibitors and periodic limb movements of sleep. Pediatr Neurol 2011;45:175-7.

56. Marcus CL, Traylor J, Gallagher PR, et al. Prevalence of periodic limb movements during sleep in normal children. Sleep 2014;37:1349-52.

57. Scholle S, Scholle HC. Leg movements and periodic leg movements during sleep in the development across childhood and adolescence from 1 to 18 years. Sleep Med 2014;15:1068-74.

58. Montgomery-Downs HE, O'Brien LM, Gulliver TE, et al. Polysomnographic characteristics in normal preschool and early school-aged children. Pediatrics 2006;117:741-53.

59. Traeger N, Schultz B, Pollock AN, et al. Polysomnographic values in children 2-9 years old: additional data and review of the literature. Pediatr Pulmonol 2005;40:22-30.

60. Burg CJ, Montgomery-Downs HE, Mettler P, et al. Respiratory and polysomnographic values in 3- to 5 -year-old normal children at higher altitude. Sleep 2013;36:1707-14.

61. Haba-Rubio J, Marti-Soler H, Marques-Vidal P, et al. Prevalence and determinants of periodic limb movements in the general population. Ann Neurol 2016;79:464-74.

62. Wasserman D, Bindman D, Nesbitt AD, et al. Striatal Dopaminergic Deficit and Sleep in Idiopathic Rapid Eye Movement Behaviour Disorder: An Explorative Study. Nat Sci Sleep 2021;13:1-9.

63. Parrino L, Boselli M, Buccino GP, et al. The cyclic alternating pattern plays a gate-control on periodic limb movements during non-rapid eye movement sleep. J Clin Neurophysiol 1996;13:314-23.

64. Parrino L, Halasz P, Tassinari CA, et al. CAP, epilepsy and motor events during sleep: the unifying role of arousal. Sleep Med Rev 2006;10:267-85.

65. Duffy JF, Lowe AS, Silva EJ, et al. Periodic limb movements in sleep exhibit a circadian rhythm that is maximal in the late evening/early night. Sleep Med 2011;12:83-8.

66. Culpepper WJ, Badia P, Shaffer JI. Time-of-night patterns in PLMS activity. Sleep 1992;15:306-11.

67. Mutti C, Ciliento R, Melpignano A, et al. Can body position and sleep stages influence motor patterns in periodic limb movement disorder? Sleep Med 2019;62:32-3.

68. Nobili L, Sartori I, Terzaghi M, et al. Intracerebral recordings of minor motor events, paroxysmal arousals and major seizures in nocturnal frontal lobe epilepsy. Neurol Sci 2005;26 Suppl 3:s215-9.

69. Tassinari CA, Gardella E, Cantalupo G, et al. Relationship 
of Central Pattern Generators with Parasomnias and Sleep-Related Epileptic Seizures. Sleep Med Clin 2012;7:125-34.

70. Carrier J, Frenette S, Montplaisir J, et al. Effects of periodic leg movements during sleep in middleaged subjects without sleep complaints. Mov Disord 2005;20:1127-32.

71. Gehrman P, Stepnowsky C, Cohen-Zion M, et al. Longterm follow-up of periodic limb movements in sleep in older adults. Sleep 2002;25:340-3.

72. Hornyak M, Trenkwalder C. Restless legs syndrome and periodic limb movement disorder in the elderly. J Psychosom Res 2004;56:543-8.

73. Moraes W, Piovezan R, Poyares D, et al. Effects of aging on sleep structure throughout adulthood: a populationbased study. Sleep Med 2014;15:401-9.

74. Kraus T, Schuld A, Pollmächer T. Periodic leg movements in sleep and restless legs syndrome probably caused by olanzapine. J Clin Psychopharmacol 1999;19:478-9.

75. Pinninti NR, Mago R, Townsend J, et al. Periodic restless legs syndrome associated with quetiapine use: a case report. J Clin Psychopharmacol 2005;25:617-8.

76. Wetter TC, Brunner H, Collado-Seidel V, et al. Sleep and periodic limb movements in corticobasal degeneration. Sleep Med 2002;3:33-6.

77. Tobback E, Desmet O, Hanoulle I, et al. Retrospective Analysis of Risk Factors for Periodic Limb Movements in a Large Cohort of Insomnia and Chronic Fatigue Patients. Pharmacopsychiatry 2020;53:71-7.

78. Yang C, White DP, Winkelman JW. Antidepressants and periodic leg movements of sleep. Biol Psychiatry 2005;58:510-4.

79. Ohayon MM, Roth T. Prevalence of restless legs syndrome and periodic limb movement disorder in the general population. J Psychosom Res 2002;53:547-54.

80. Moore H 4th, Winkelmann J, Lin L, et al. Periodic leg movements during sleep are associated with polymorphisms in BTBD9, TOX3/BC034767, MEIS1, MAP2K5/SKOR1, and PTPRD. Sleep 2014;37:1535-42.

81. Benz RL, Pressman MR, Hovick ET, et al. Potential novel predictors of mortality in end-stage renal disease patients with sleep disorders. Am J Kidney Dis 2000;35:1052-60.

82. Lindner A, Fornadi K, Lazar AS, et al. Periodic limb movements in sleep are associated with stroke and cardiovascular risk factors in patients with renal failure. J Sleep Res 2012;21:297-307.

83. Wilson D, Walker S, Fung A, et al. Periodic limb movements in sleep during pregnancy: a common but benign disorder? Sleep Biol Rhythms 2018;16:11-20.

84. Hornyak M, Voderholzer U, Hohagen F, et al. Magnesium therapy for periodic leg movements-related insomnia and restless legs syndrome: an open pilot study. Sleep 1998;21:501-5.

85. Liu S, Pan J, Tang K, et al. Sleep spindles, K-complexes, limb movements and sleep stage proportions may be biomarkers for amnestic mild cognitive impairment and Alzheimer's disease. Sleep Breath 2020;24:637-51.

86. EKBOM KA. Restless legs syndrome. Neurology 1960;10:868-73.

87. Matthews WB. Letter: Iron deficiency and restless legs. $\mathrm{Br}$ Med J 1976;1:898.

88. NORDLANDER NB. Therapy in restless legs. Acta Med Scand 1953;145:453-57.

89. Szentkirályi A, Stefani A, Hackner H, et al. Prevalence and associated risk factors of periodic limb movement in sleep in two German population-based studies. Sleep 2019;42:zsy237.

90. Koo BB, Mehra R, Blackwell T, et al. Periodic limb movements during sleep and cardiac arrhythmia in older men (MrOS sleep). J Clin Sleep Med 2014;10:7-11.

91. Leary EB, Moore HE 4th, Schneider LD, et al. Periodic limb movements in sleep: Prevalence and associated sleepiness in the Wisconsin Sleep Cohort. Clin Neurophysiol 2018;129:2306-14.

92. Claman DM, Ewing SK, Redline S, et al. Periodic leg movements are associated with reduced sleep quality in older men: the MrOS Sleep Study. J Clin Sleep Med 2013;9:1109-17.

93. Shin JW, Koo YS, Lee BU, et al. Prevalence and Characteristics of Periodic Limb Movements during Sleep in Korean Adult Patients with Restless Legs Syndrome. J Clin Sleep Med 2016;12:1089-97.

94. Gingras JL, Gaultney JF, Picchietti DL. Pediatric periodic limb movement disorder: sleep symptom and polysomnographic correlates compared to obstructive sleep apnea. J Clin Sleep Med 2011;7:603-9A.

95. Picchietti DL, Stevens HE. Early manifestations of restless legs syndrome in childhood and adolescence. Sleep Med 2008;9:770-81.

96. Picchietti MA, Picchietti DL, England SJ, et al. Children show individual night-to-night variability of periodic limb movements in sleep. Sleep 2009;32:530-5.

97. O'Brien LM, Holbrook CR, Faye Jones V, et al. Ethnic difference in periodic limb movements in children. Sleep Med 2007;8:240-6.

98. Wong MW, Williamson BD, Qiu W, et al. Growing 
pains and periodic limb movements of sleep in children. J Paediatr Child Health 2014;50:455-60.

99. Sharon D, Walters AS, Simakajornboon N. Restless Legs Syndrome and Periodic Limb Movement Disorder in Children. J Child Sci 2019;9:e38-49.

100. Gaultney JF, Merchant K, Gingras JL. Parents of children with periodic limb movement disorder versus sleepdisordered breathing report greater daytime mood and behavior difficulties in their child: the importance of using ICSD-2nd Edition criteria to define a PLMD study group. Behav Sleep Med 2009;7:119-35.

101. Begum E, Goodday A, Spurr K, et al. Periodic Limb Movements of Sleep in Children with Attention-Deficit/ Hyperactivity Disorder: Baseline Frequency and Impact of PsychoStimulant Medication. SM J Sleep Disord 2018;4:1019.

102. Crabtree VM, Ivanenko A, O'Brien LM, et al. Periodic limb movement disorder of sleep in children. J Sleep Res 2003;12:73-81.

103. Miano S, Esposito M, Foderaro G, et al. Sleep-Related Disorders in Children with Attention-Deficit Hyperactivity Disorder: Preliminary Results of a Full Sleep Assessment Study. CNS Neurosci Ther 2016;22:906-14.

104. Spruyt K, Gozal D. Sleep disturbances in children with attention-deficit/hyperactivity disorder. Expert Rev Neurother 2011;11:565-77.

105. Rosenzweig I, Glasser M, Polsek D, et al. Sleep apnoea and the brain: a complex relationship. Lancet Respir Med 2015;3:404-14.

106. Earley CJ, Silber MH. Restless legs syndrome: understanding its consequences and the need for better treatment. Sleep Med 2010;11:807-15.

107.Lin CC, Chou CH, Fan YM, et al. Increased Risk of Dementia Among Sleep-Related Movement Disorders: A Population-Based Longitudinal Study in Taiwan. Medicine (Baltimore) 2015;94:e2331.

108. Ferini-Strambi L, Filippi M, Martinelli V, et al. Nocturnal sleep study in multiple sclerosis: correlations with clinical and brain magnetic resonance imaging findings. J Neurol Sci 1994;125:194-7.

109. Nam H, Hong YH, Kwon HM, et al. Sleep Pattern of Patients with Multiple System Atrophy. J Korean Sleep Res Soc 2006;3:79-84.

110.Lo Coco D, Puligheddu M, Mattaliano P, et al. REM sleep behavior disorder and periodic leg movements during sleep in ALS. Acta Neurol Scand 2017;135:219-24.

111.De Mello MT, Silva AC, Esteves AM, et al. Reduction of periodic leg movement in individuals with paraplegia following aerobic physical exercise. Spinal Cord 2002;40:646-9.

112. Rivière JB, Xiong L, Levchenko A, et al. Association of intronic variants of the BTBD9 gene with Tourette syndrome. Arch Neurol 2009;66:1267-72.

113. Voderholzer U, Müller N, Haag C, et al. Periodic limb movements during sleep are a frequent finding in patients with Gilles de la Tourette's syndrome. J Neurol 1997;244:521-6.

114. Coelho FM, Georgsson H, Narayansingh M, et al. Higher prevalence of periodic limb movements of sleep in patients with history of stroke. J Clin Sleep Med 2010;6:428-30.

115. Okura K, Lavigne GJ, Huynh N, et al. Comparison of sleep variables between chronic widespread musculoskeletal pain, insomnia, periodic leg movements syndrome and control subjects in a clinical sleep medicine practice. Sleep Med 2008;9:352-61.

116.Pajediene E, Bileviciute-Ljungar I, Friberg D. Sleep patterns among patients with chronic fatigue: A polysomnography-based study. Clin Respir J 2018;12:1389-97.

117. Besteiro González JL, Suárez Fernández TV, Arboleya Rodríguez L, et al. Sleep architecture in patients with fibromyalgia. Psicothema 2011;23:368-73.

118.Jee HJ, Shin W, Jung HJ, et al. Impact of Sleep Disorder as a Risk Factor for Dementia in Men and Women. Biomol Ther (Seoul) 2020;28:58-73.

119. Lyu S, Xing H, DeAndrade MP, et al. The Role of BTBD9 in the Cerebellum, Sleep-like Behaviors and the Restless Legs Syndrome. Neuroscience 2020;440:85-96.

120.Leng Y, Blackwell T, Stone KL, et al. Periodic Limb Movements in Sleep are Associated with Greater Cognitive Decline in Older Men without Dementia. Sleep 2016;39:1807-10.

121. Wetter TC, Collado-Seidel V, Pollmächer T, et al. Sleep and periodic leg movement patterns in drug-free patients with Parkinson's disease and multiple system atrophy. Sleep 2000;23:361-7.

122. Yang X, Liu B, Shen H, et al. Prevalence of restless legs syndrome in Parkinson's disease: a systematic review and meta-analysis of observational studies. Sleep Med 2018;43:40-6.

123. Happe S, Pirker W, Klösch G, et al. Periodic leg movements in patients with Parkinson's disease are associated with reduced striatal dopamine transporter binding. J Neurol 2003;250:83-6.

124. Veauthier C, Gaede G, Radbruch H, et al. Periodic limb movements during REM sleep in multiple sclerosis: a 
previously undescribed entity. Neuropsychiatr Dis Treat 2015;11:2323-9.

125. Castelnovo A, Ferri R, Tanioka K, et al. 1122 Sleep Architecture and Leg Movement Activity During Sleep in Patients with Multiple Sclerosis. Sleep 2020;43:A427-8.

126. Srinivasan J, Giannuzzi A, Cascone A, et al. Periodic Limb Movements in People with Multiple Sclerosis Who Report Fatigue: Polysomnography Study in a Large Cohort. ECTRIMS Online Library, 2019.

127. Lee HB, Song ML, Koo BB, et al. Mood Symptoms and Restless Legs Syndrome Without Periodic Limb Movements During Sleep: Is it a Clinical Subtype? J Neuropsychiatry Clin Neurosci 2017;29:52-9.

128. Baumann CR, Marti I, Bassetti CL. Restless legs symptoms without periodic limb movements in sleep and without response to dopaminergic agents: a restless legslike syndrome? Eur J Neurol 2007;14:1369-72.

129. Cho YW, Song ML, Earley CJ, et al. Prevalence and clinical characteristics of patients with restless legs syndrome with painful symptoms. Sleep Med 2015;16:775-8.

130. Byun JI, Kim JS, Shin YY, et al. Difference in psychological distress between patients with periodic limb movement disorder and restless legs syndrome. Sleep Med Res 2019;10:25-30.

131. Cavagnolli DA, Esteves AM, Castiglione ML, et al. Dopamine transporter shown by SPECT in patients with periodic leg movement after acute physical exercise. Med Sci Sports Exerc 2013;45:224-9.

132. Esteves AM, de Mello MT, Pradella-Hallinan M, et al. Effect of acute and chronic physical exercise on patients with periodic leg movements. Med Sci Sports Exerc 2009;41:237-42.

133. Lavigne GL, Lobbezoo F, Rompré PH, et al. Cigarette smoking as a risk factor or an exacerbating factor for restless legs syndrome and sleep bruxism. Sleep 1997;20:290-3.

134. Nofzinger EA, Fasiczka A, Berman S, et al. Bupropion SR reduces periodic limb movements associated with arousals from sleep in depressed patients with periodic limb movement disorder. J Clin Psychiatry 2000;61:858-62.

135. Hoque R, Chesson AL Jr. Pharmacologically induced/ exacerbated restless legs syndrome, periodic limb movements of sleep, and REM behavior disorder/REM sleep without atonia: literature review, qualitative scoring, and comparative analysis. J Clin Sleep Med 2010;6:79-83.

136. Li J, Moore H 4th, Lin L, et al. Association of low ferritin with PLM in the Wisconsin Sleep Cohort. Sleep Med
2015;16:1413-8.

137.Allen RP, Picchietti DL, Auerbach M, et al. Evidencebased and consensus clinical practice guidelines for the iron treatment of restless legs syndrome/Willis-Ekbom disease in adults and children: an IRLSSG task force report. Sleep Med 2018;41:27-44.

138. Sforza E, Nicolas A, Lavigne G, et al. EEG and cardiac activation during periodic leg movements in sleep: support for a hierarchy of arousal responses. Neurology 1999;52:786-91.

139. Sieminski M, Pyrzowski J, Partinen M. Periodic limb movements in sleep are followed by increases in EEG activity, blood pressure, and heart rate during sleep. Sleep Breath 2017;21:497-503.

140. Winkelman JW. The evoked heart rate response to periodic leg movements of sleep. Sleep 1999;22:575-80.

141.Ferri R, Zucconi M, Rundo F, et al. Heart rate and spectral EEG changes accompanying periodic and nonperiodic leg movements during sleep. Clin Neurophysiol 2007;118:438-48.

142.Ferrillo F, Beelke M, Canovaro P, et al. Changes in cerebral and autonomic activity heralding periodic limb movements in sleep. Sleep Med 2004;5:407-12.

143. Sasai T, Matsuura M, Inoue Y. Change in heart rate variability precedes the occurrence of periodic leg movements during sleep: an observational study. BMC Neurol 2013;13:139.

144. Manconi M, Ferri R, Zucconi M, et al. Dissociation of periodic leg movements from arousals in restless legs syndrome. Ann Neurol 2012;71:834-44.

145. Ferri R, Manconi M, Aricò D, et al. Acute dopamineagonist treatment in restless legs syndrome: effects on sleep architecture and NREM sleep instability. Sleep 2010;33:793-800.

146. Terzano MG, Parrino L, Boselli M, et al. Polysomnographic analysis of arousal responses in obstructive sleep apnea syndrome by means of the cyclic alternating pattern. J Clin Neurophysiol 1996;13:145-55.

147. de Weerd AW, Rijsman RM, Brinkley A. Activity patterns of leg muscles in periodic limb movement disorder. J Neurol Neurosurg Psychiatry 2004;75:317-9.

148.Lugaresi E, Cirignotta F, Coccagna G, et al. Nocturnal myoclonus and restless legs syndrome. Adv Neurol 1986;43:295-307.

149. Provini F, Vetrugno R, Meletti S, et al. Motor pattern of periodic limb movements during sleep. Neurology 2001;57:300-4.

150.Ferri R, Proserpio P, Rundo F, et al. Neurophysiological 
correlates of sleep leg movements in acute spinal cord injury. Clin Neurophysiol 2015;126:333-8.

151.Gültekin M, Ismailoğullari S, Aksu M. Comparison of motor pattern of periodic limb movements in patients with restless legs syndrome and obstructive sleep apnea syndrome. Turk J Med Sci 2014;44:1067-72.

152. Calancie B. Spinal myoclonus after spinal cord injury. J Spinal Cord Med 2006;29:413-24.

153. Heide AC, Winkler T, Helms HJ, et al. Effects of transcutaneous spinal direct current stimulation in idiopathic restless legs patients. Brain Stimul 2014;7:636-42.

154. Guggisberg AG, Hess CW, Mathis J. The significance of the sympathetic nervous system in the pathophysiology of periodic leg movements in sleep. Sleep 2007;30:755-66.

155. Kim TJ, Cha KS, Lee S, et al. Brain regions associated with periodic leg movements during sleep in restless legs syndrome. Sci Rep 2020;10:1615.

156. Schulte EC, Kaffe M, Schormair B, et al. Iron in Restless Legs Syndrome. Mov Disord Clin Pract 2014;1:161-72.

157. Guo S, Huang J, Jiang H, et al. Restless Legs Syndrome: From Pathophysiology to Clinical Diagnosis and Management. Front Aging Neurosci 2017;9:171.

158. Galbiati A, Marelli S, Giora E, et al. Neurocognitive function in patients with idiopathic Restless Legs Syndrome before and after treatment with dopamineagonist. Int J Psychophysiol 2015;95:304-9.

159.Paulus W, Trenkwalder C. Less is more: pathophysiology of dopaminergic-therapy-related augmentation in restless legs syndrome. Lancet Neurol 2006;5:878-86.

160. Allen RP, Ondo WG, Ball E, et al. Restless legs syndrome (RLS) augmentation associated with dopamine agonist and levodopa usage in a community sample. Sleep Med 2011;12:431-9.

161. Winkelmann J, Schadrack J, Wetter TC, et al. Opioid and dopamine antagonist drug challenges in untreated restless legs syndrome patients. Sleep Med 2001;2:57-61.

162. Garcia-Borreguero D, Williams AM. An update on restless legs syndrome (Willis-Ekbom disease): clinical features, pathogenesis and treatment. Curr Opin Neurol 2014;27:493-501.

163. Dauvilliers Y, Winkelmann J. Restless legs syndrome: update on pathogenesis. Curr Opin Pulm Med 2013;19:594-600.

164. Unger EL, Bianco LE, Jones BC, et al. Low brain iron effects and reversibility on striatal dopamine dynamics. Exp Neurol 2014;261:462-8.

165. Georgieff MK. The role of iron in neurodevelopment: fetal iron deficiency and the developing hippocampus.
Biochem Soc Trans 2008;36:1267-71.

166.Lozoff B. Early iron deficiency has brain and behavior effects consistent with dopaminergic dysfunction. J Nutr 2011;141:740S-6S.

167. Clemens S, Hochman S. Conversion of the modulatory actions of dopamine on spinal reflexes from depression to facilitation in D3 receptor knock-out mice. J Neurosci 2004;24:11337-45.

168. Holstege JC, Van Dijken H, Buijs RM, et al. Distribution of dopamine immunoreactivity in the rat, cat and monkey spinal cord. J Comp Neurol 1996;376:631-52.

169. Ondo WG, He Y, Rajasekaran S, et al. Clinical correlates of 6-hydroxydopamine injections into A11 dopaminergic neurons in rats: a possible model for restless legs syndrome. Mov Disord 2000;15:154-8.

170.Sun YM, Hoang T, Neubauer JA, et al. Opioids protect against substantia nigra cell degeneration under conditions of iron deprivation: a mechanism of possible relevance to the Restless Legs Syndrome (RLS) and Parkinson's disease. J Neurol Sci 2011;304:93-101.

171. Allen RP, Barker PB, Horská A, et al. Thalamic glutamate/ glutamine in restless legs syndrome: increased and related to disturbed sleep. Neurology 2013;80:2028-34.

172. Yepes G, Guitart X, Rea W, et al. Targeting hypersensitive corticostriatal terminals in restless legs syndrome. Ann Neurol 2017;82:951-60.

173. Winkelman JW, Bogan RK, Schmidt MH, et al. Randomized polysomnography study of gabapentin enacarbil in subjects with restless legs syndrome. Mov Disord 2011;26:2065-72.

174.Ill AM, Mitchell TR, Neely EB, et al. Metabolic analysis of mouse brains that have compromised iron storage. Metab Brain Dis 2006;21:77-87.

175.Ward KL, Tkac I, Jing Y, et al. Gestational and lactational iron deficiency alters the developing striatal metabolome and associated behaviors in young rats. J Nutr 2007;137:1043-9.

176. Bonati MT, Ferini-Strambi L, Aridon P, et al. Autosomal dominant restless legs syndrome maps on chromosome 14q. Brain 2003;126:1485-92.

177. Desautels A, Turecki G, Montplaisir J, et al. Identification of a major susceptibility locus for restless legs syndrome on chromosome 12q. Am J Hum Genet 2001;69:1266-70.

178. Dhawan V, Ali M, Chaudhuri KR. Genetic aspects of restless legs syndrome. Postgrad Med J 2006;82:626-9.

179.Jiménez-Jiménez FJ, Alonso-Navarro H, García-Martín E, et al. Latest perspectives in genetic risk factors for restless legs syndrome. Eur Neurol Rev 2013;8:90-6. 
180. Winkelmann J, Lichtner P, Schormair B, et al. Variants in the neuronal nitric oxide synthase (nNOS, NOS1) gene are associated with restless legs syndrome. Mov Disord 2008;23:350-8.

181. Catoire H, Dion PA, Xiong L, et al. Restless legs syndrome-associated MEIS1 risk variant influences iron homeostasis. Ann Neurol 2011;70:170-5.

182.Freeman A, Pranski E, Miller RD, et al. Sleep fragmentation and motor restlessness in a Drosophila model of Restless Legs Syndrome. Curr Biol 2012;22:1142-8.

183.Paulus W, Dowling P, Rijsman R, et al. Pathophysiological concepts of restless legs syndrome. Mov Disord 2007;22:1451-6.

184. Silver N, Allen R, Earley CJ. MEIS1 as a potential mediator of the RLS-iron pathology. Mov Disord 2010;25:S513-4.

185. Uetani N, Chagnon MJ, Kennedy TE, et al. Mammalian motoneuron axon targeting requires receptor protein tyrosine phosphatases sigma and delta. J Neurosci 2006;26:5872-80.

186. Winkelmann J, Czamara D, Schormair B, et al. Genomewide association study identifies novel restless legs syndrome susceptibility loci on 2p14 and 16q12.1. PLoS Genet 2011;7:e1002171.

187. Winkelmann J, Schormair B, Lichtner P, et al. Genomewide association study of restless legs syndrome identifies common variants in three genomic regions. Nat Genet 2007;39:1000-6.

188. Yuan SH, Qiu Z, Ghosh A. TOX3 regulates calciumdependent transcription in neurons. Proc Natl Acad Sci U
S A 2009;106:2909-14.

189. Ondo W, Jankovic J. Restless legs syndrome: clinicoetiologic correlates. Neurology 1996;47:1435-41.

190. Winkelmann J, Wetter TC, Collado-Seidel V, et al. Clinical characteristics and frequency of the hereditary restless legs syndrome in a population of 300 patients. Sleep 2000;23:597-602.

191.Parish JM. Genetic and immunologic aspects of sleep and sleep disorders. Chest 2013;143:1489-99.

192. Xiong L, Montplaisir J, Desautels A, et al. Family study of restless legs syndrome in Quebec, Canada: clinical characterization of 671 familial cases. Arch Neurol 2010;67:617-22.

193.Hawrylycz MJ, Lein ES, Guillozet-Bongaarts AL, et al. An anatomically comprehensive atlas of the adult human brain transcriptome. Nature 2012;489:391-9.

194. Schormair B, Kemlink D, Roeske D, et al. PTPRD (protein tyrosine phosphatase receptor type delta) is associated with restless legs syndrome. Nat Genet 2008;40:946-8.

195. Stefansson H, Rye DB, Hicks A, et al. A genetic risk factor for periodic limb movements in sleep. N Engl J Med 2007;357:639-47.

196. Dasen JS, Tice BC, Brenner-Morton S, et al. A Hox regulatory network establishes motor neuron pool identity and target-muscle connectivity. Cell 2005;123:477-91.

197. Winkelman JW, Finn L, Young T. Prevalence and correlates of restless legs syndrome symptoms in the Wisconsin Sleep Cohort. Sleep Med 2006;7:545-52.

198. Lyu S, Xing H, DeAndrade MP, et al. The Role of BTBD9 in Striatum and Restless Legs Syndrome. eNeuro 2019;6:ENEURO.
Cite this article as: Drakatos $\mathrm{P}$, Olaithe $\mathrm{M}$, Verma D, Ilic K, Cash D, Fatima Y, Higgins S, Young AH, Chaudhuri KR, Steier J, Skinner T, Bucks R, Rosenzweig I. Periodic limb movements during sleep: a narrative review. J Thorac Dis 2021;13(11):6476-6494. doi: 10.21037/jtd-21-1353 